\title{
Premenstrual symptoms among students in health institutions in Zaria, northern Nigeria
}

\author{
Hajaratu U. Sulayman ", Nana H. Madugu, Abimbola O. D. Kolawole, Polite Onwuhafua \\ Department of Obstetrics \& Gynaecology, Ahmadu Bello University Teaching Hospital, Shika, Zaria, Nigeria. West Africa
}

Email address:

hajaratuumar@gmail.com (H. U. Sulayman)

\section{To cite this article:}

Hajaratu U. Sulayman, Nana H. Madugu, Abimbola O. D. Kolawole, Polite Onwuhafua. Premenstrual Symptoms among Students in Health Institutions in Zaria, Northern Nigeria. Journal of Gynecology and Obstetrics. Vol. 3, No. 1, 2015, pp. 1-5.

doi: 10.11648/j.jgo.20150301.11

\begin{abstract}
Introduction: About $90 \%$ of menstruating women get advanced warning of an approaching period because of the physical and/or psychological changes in the days before the period begins. Many women have mild symptoms and in a few it may be severe. This study intends to find the commonest symptoms among students in health institutions in Zaria, Northern Nigeria. Objective: To determine the commonest premenstrual symptoms among students in health institutions in Zaria. Methods: A cross sectional study was carried out in some health institution in Zaria Northern Nigeria over a three month period. A total of 300 students were interviewed using semi structured open ended questionnaires. Information about premenstrual symptoms were sought. The criteria for the diagnosis of (Premenstrual Syndrome) PMS was based on the Diagnostic and Statistical Manual of Mental Disorder (DSM IV Manual). Data was analyzed using computer software SPSS version 20. Results: Medical students constituted 42.7\%, Nursing 28.6\%, Medical Laboratory $27.8 \%$ and Medical Records $0.9 \%$.Their age range was 18 to 29 years with a mean age of $20 \pm 3$ years. The mean age of menarche was 13.7 years (SD 2.1). The prevalence of PMS was $40.7 \%$. The major tribes (Hausa/ Fulani, Igbo and Yoruba) were more likely to have the above symptoms than both the Northern and Southern minorities. The commonest symptoms was abdominal pain/discomfort as seen in $180(70.6 \%)$ of the respondents. Tiredness $158(61.0 \%)$ and painful/tender breasts $149(57.1 \%)$ were also common. Fifty seven percent (57.3\%) 141 of them had severe symptoms warranting drug use while $8(3.7 \%)$ had to be admitted in the hospital. The use of drugs for the above symptoms as well as the hospitalization rate was not statistically significant. Conclusions: Both physical and psychological premenstrual symptoms were found among these students which affected their quality of life. To what extent these symptoms affect studies and family life in our environment requires further research.
\end{abstract}

Keywords: Premenstrual Symptoms, Students, Health Institution

\section{Introduction}

Only recently was Premenstrual Syndrome (PMS) accepted as a serious condition due to failure to distinguish true PMS from milder physiological premenstrual symptoms seen in majority the of women. ${ }^{1}$ Premenstrual symptoms occur in $95 \%$ of all women of the reproductive age while PMS occurs in about $5 \%$ of these women. ${ }^{1}$ Premenstrual tension is the lay term in common use to describe PMS while Premenstrual Dysphoric Disorder (PMDD) according to the Fourth Edition of the Diagnostic and Statistical Manual of Mental Disorder (DSM IV Manual) is the extreme predominantly psychological end of the PMS estimated to occur in $3 \%$ to $9 \%$ of women. ${ }^{2-6}$

Over the last 60 years, research has been directed towards establishing the causes and generating effective treatments for PMS. Its recognition is a twentieth-century event, reflecting changes in our social structure and lifestyle. In the past, the time between puberty and the menopause was filled with many pregnancies when PMS disappears. Each was followed by the cessation of ovulation caused by prolonged breastfeeding. ${ }^{2,}{ }^{7}$ In the present day, with fewer pregnancies, the effects of the menstrual cycle are more apparent. ${ }^{7}$

Studies have shown that most women experience premenstrual symptoms during their reproductive years, but not all perceive PMS as debilitating or distressing. However, $5-10 \%$ of women - approximately 1.5 million women in the UK - suffer from such severe premenstrual symptoms or premenstrual dysphoric disorder (PMDD) that their work, relationships and social lives are impaired. ${ }^{7,8}$ 
PMS is said to be a constellation of recurrent physical, emotional or behavioural (psychological and or somatic) symptoms occurring specifically during the luteal phase of the menstrual cycle and resolving by the end of menstruation. There must be a symptom free interval of at least one week during the first half (follicular phase) of the menstrual cycle. Although these conditions are not life threatening, the symptoms can be so severe that they disrupt the patient's normal functioning, quality of life, mental health, productivity and interpersonal relationships. ${ }^{7,9,10}$

Over 150 symptoms have been attributed to PMS. After complaints of feeling "out-of-control", anxious, depressed and having uncontrollable crying spells, the most common complaints are headache and fatigue. But symptoms may vary from month to month and there may even be symptomfree months. No woman present with all the PMS symptoms. Characteristically symptoms may be both physical and emotional. They may include physical symptoms as headache migraine, fluid retention, fatigue, constipation, painful joints, backache, abdominal cramping, heart palpitations and weight gain. Emotional and behavioural changes may include anxiety, depression, irritability, panic attacks, tension, lack of co-ordination, decreased work or social performance and altered libido. ${ }^{1,2,7,9}$ Somatic symptoms include bloatedness, breast swelling and pain, pelvic pain, headache, skin disorders, and change in bowel habits and psychological symptoms may include aggressiveness, inability to concentrate, hypersomnia or insomnia, change in appetite and specific food craving and increased craving for cigarette smoking. ${ }^{10-15}$

The main aim of this study was to assess and document the prevalence of PMS among students in the Northern part of Nigeria as few studies have been done in this area.

\section{Methodology}

Four institutions were randomly selected from a list of Health Institutions in Kaduna State, Northern Nigeria after the sample size was determined to be 300 . This was a descriptive cross sectional study using convenient sampling in which semi-structured self- administered questionnaires were given to female undergraduate students who gave their consent in the Faculty of Medicine, School of Nursing, School of Medical Laboratory Sciences and School of Medical Records were interviewed. The questionnaires were initially pretested in another school (not used in the study) and modifications were made. Only students present at the time of the interview were administered the questionnaires. Ethic clearance was obtained from the Ahmadu Bello University Teaching Hospital Ethics committee.

The criteria for the diagnosis of PMS were based on the Diagnostic and Statistical Manual of Mental Disorder (DSM IV Manual).

The data obtained was analyzed using SPSS 20.0 statistical software. The P value of significance was set at 0.05 .

\section{Results}

Of the 300 questionnaires administered only 262 were fit for analysis after cleaning of the data.

Medical students were 112 (42. 7\%), Nursing students were 75 (28.6\%), Medical Laboratory Science students were $73(27.8 \%)$ and Medical Records students were 2 (0.9\%). See Figure 1.

\section{CADRE OF STUDENTS}

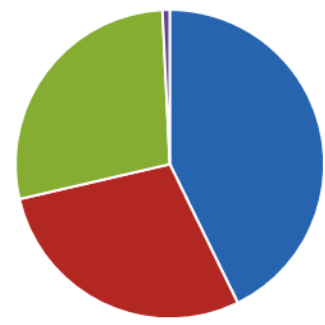

- Medical Students - Nursing Students
- Medical Laboratory Science Students — Medical Records Students

Figure 1. Cadre of Students Interviewed

The Hausa/Fulani tribe were the largest in number; 95 (36.6\%) followed by the Northern Minority; 72 (27.1\%). Most participants were unmarried 240 (91.7\%). See Tables 1 and 2 .

Table 1. Ethnic Groups

\begin{tabular}{lll}
\hline Ethnic Group & Number & Percentage \\
\hline Hausa/Fulani & 95 & 36.3 \\
Yoruba & 40 & 15.3 \\
Igbo & 38 & 14.3 \\
Northern Minority & 72 & 27.1 \\
Southern Minority & 17 & 6.5 \\
Total & 262 & 100 \\
\hline
\end{tabular}

Table 2. Marital Status

\begin{tabular}{lll}
\hline Marital Status & Number & Percentage \\
\hline Never Married & 240 & $91.7 \%$ \\
Married & 20 & $7.6 \%$ \\
Divorced & 2 & 0.7 \\
\hline
\end{tabular}

Their age range was between 18 and 29 years with a mean age of $20 \pm 3$ years. The mean age of menarche was 13.7 years with a standard deviation of 2.1. The prevalence of PMS in this study according to the DSM IV criteria was $40.7 \%$. There was no statistical difference in the occurrence of symptoms across the groups.

The commonest symptoms was abdominal pain/discomfort as seen in $180(70.6 \%)$ of the respondents. Tiredness 158 $(61.0 \%)$ and painful/tender breasts $149(57.1 \%)$ were also common. Fifty seven percent (57.3\%) 141 of them had severe symptoms warranting drug use while $8(3.7 \%)$ had to be admitted in the hospital. One hundred and one (40.7\%) of these students said these symptoms interfered with their daily activities. See Figure 2. 


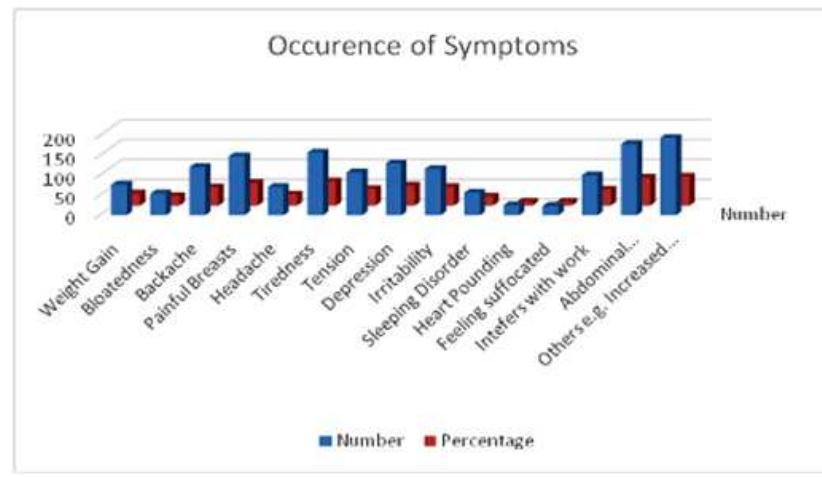

Figure 2. Types of Symptoms experienced

There was a significant association seen when tribe was cross tabulated with all the symptoms with weight gain, tiredness, abdominal pain and mood changes being more likely to occur among the major tribes (Hausa/ Fulani, Igbo and Yoruba) than both the Northern and Southern minorities. The use of drugs for the above symptoms as well as the hospitalization rate was not statistically significant. See Table 3

Table 3. Association Between Symptom And Tribe

\begin{tabular}{ll}
\hline Symptom & P Value \\
\hline Weight Gain & 0.002 \\
Tiredness & 0.041 \\
Abdominal Pain & 0.017 \\
Mood Changes & 0.028 \\
Use of Drugs & 0.172 \\
Hospitalization & 0.173 \\
\hline
\end{tabular}

Two hundred and fifty two (95.1\%) had regular menstruation. Fifty nine respondents $(24.4 \%)$ were sexually active.

\section{Discussion}

Premenstrual Syndrome primarily affects those in their late twenties and early thirties without racial, socioeconomic or other demographic predilection. ${ }^{16-18}$ This was seen in our study as most of the respondents were in their 20s. Severe PMS is more common between the ages of 30 and 40 years, and in women with young children. PMS is rarely encountered in adolescents. ${ }^{19}$ It is said to affect the quality of life of up to $40 \%$ of women of childbearing age. ${ }^{20}$

The prevalence of PMS in this study according to the DSM IV criteria was $40.7 \%$. This was slightly higher than $37.0 \%$ seen in another African study by Tolossa et al in Ethiopia. ${ }^{21}$

PMS is said to be commoner among whites and smokers and in the obese (BMI above 30), there is a three-fold risk for the development of this disorder. 22 Women with PMS are also said to be at a greater risk of menopausal hot flushes, depressed mood, poor sleep and decreased libido.23 Hysterectomized patients can still have PMS if at least one ovary is present. $2,7,24$

Some studies have shown prevalence of over $50 \%$ of symptoms that include irritability, abdominal discomfort, nervousness, headache, breast pain and fatigue. ${ }^{3,25,26}$ The commonest symptoms in our study were abdominal pain, tiredness, painful breasts, depression and irritability.

Contrary to Western findings it has been shown in Africa that a significant majority of women with PMS reported more physical than emotional complaints. This is explainable in terms of the widely held view that psychic conflicts in the indigenous African are often somatised. This was illustrated in our study as respondents had more physical symptoms (abdominal pain, tiredness and painful breasts) than emotional (irritability and depression); though the occurrence of the emotional symptoms was also significant.

Marriage and history of pregnancy have suppressing effects on the premenstrual physical complaints, mood disturbance and impairment of social functioning. This psychosomatic buffering might be due to higher premium attached to marriage and child bearing as indices of fulfilled living in traditional setting in Africa. ${ }^{27}$

The aetiology of PMS is unknown. Changes in the levels of some hormones and their metabolites such as Prolactin, Oestrogen, Progesterone, Endorphins, and Prostaglandins, and their interactions with neurotransmitters and neurohormonal systems such as Serotonin, GABA, Cholecystokinin and the Renin-angiotensin-aldosterone system have been proposed. ${ }^{2}$, ${ }^{28}$ Many current treatments aim to alter the levels of these hormones such as the use of oral contraceptives, Progesterone, Bromocriptine, Prostaglandin synthetase inhibitors (especially mefenamic acid) and danazol. ${ }^{2}$ Treatments that suppress ovulation have been found to be effective for premenstrual symptoms. $^{29,}{ }^{30}$ Some authors in an Australian study have suggested some psychological coping methods. ${ }^{31}$

Because PMS continues after hysterectomy if the ovaries are conserved, but disappears during pregnancy, with drugsuppressed ovulation and after the menopause when the ovaries are removed, gonadal hormones seem to be causal. However, no significant hormonal differences between those with PMS and those without the disorder have been found. ${ }^{2,7}$ The current consensus is that PMS is the result of reaction to normal hormonal, biological and environmental change in susceptible women. The pathogenesis is said to involve altered central neuroregulation and disordered homeostasis. This viewpoint has encouraged the investigation of neuroendocrine modulated central neurotransmitters and the role of the hypothalamic-pituitary-gonadal axis in PMDD. 2, 7, 29

The absence of specific tests for PMS and inconsistent acknowledgement of over 150 symptoms contribute to the difficulty in diagnosis, which relies on charting the timing of symptoms and menstruation hence the wide range of symptoms seen in our study was not unexpected. Symptoms arise during the luteal phase of the menstrual cycle. If behavioural symptoms persist throughout the menstrual cycle then the disorder might be psychological or psychiatric. ${ }^{7}$

\section{Conclusion}

Both physical and psychological premenstrual symptoms were found among students in Northern Nigeria which 
affected their quality of life. This shows that PMS actually exists in our environment. To what extent these symptoms affect studies and family life in our environment need further research.

\section{References}

[1] Ismail KMK, O’Brien PMS. Premenstrual Syndrome, Problem based learning in Gynaecology; Current Obstetrics \& Gynaecology, Harcourt Publishers Ltd U.K. 2001; 11: 251-255.

[2] Ismail KMK, O’Brien PMS. Premenstrual Syndrome. Current Obstetrics \& Gynaecology. Elservier Science Publishers. 2005; 15: $25-30$

[3] Antai AB, Udezi AW, Ekanem EE, Okon UJ, Umoiyoho AU. Premenstrual Syndrome: Prevalence in students of the University of Calabar, Nigeria.Afr. J. Biomed. Research. 2004; 7: 45-50.

[4] Mishell DR Jr. Premenstrual Disorders: Epidemiology and Disease Burden. Am J. Manag. Care Dec. 2005;11(16): S473-9

[5] Meaden PM, Hartlage SA, Cook-Karr J. Timing and severity of symptoms associated with the menstrual cycle in community-based sample in the Midwestern United States. Pshchiatry Res. Mar. 2005; 30; 134 (1) 27-36.

[6] Daugherty J.E MD. Treatment strategies for Premenstrual Syndrome. American Family Physician. July 1998; (58):1

[7] George J. Treatment Approaches to Premenstrual Syndrome. Positive Health Publications Ltd. 1994-2002. jogeorge.chinesemedicine.fsmail.net.

[8] Gingnell M, Ahlstedt V, Bannbers E, Wikström J, SundströmPoromaa I and FredriksonM.Social stimulation and corticolimbic reactivity in premenstrual dysphoric disorder: apreliminary study. BioMed Central Ltd. Biology of Mood \& Anxiety Disorders 2014; 4:3http://www.biolmoodanxietydisord.com/content/4/1/3.

[9] Lichten ED. M.D. Medical Treatment of PMS Premenstrual Syndrome. US Doctor on the Internet. drlichten@yahoo.com Last Updated June 17, 2005.

[10] McHichialami KH, Tahiri SM, Moussaoui D, et al. Assessment of premenstrual dysphoric disorder symptoms: population of women in Casablanca (English abstract only).Encephale 2002; 28 (6): 252-30.

[11] Cronje HS, Krintzinger IE. Menstruation: symptoms, management and attitudes in university students.Int J Gynecol Obstet. 1991; 35 (2):147-50.

[12] Khella AK. Epidemiologic study of premenstrual symptoms.J Egypt Public Health Assoc. 1992; 67 (1-2): 109-18.

[13] Cenac A, Maikibi DK, Develoux M.Premenstrual syndrome in Sahelian Africa. A comparative study of 400 literate and illiterate women in Niger.Trans R Soc Trop Med Hygiene. 1987; 81 (4): 544-7.

[14] Sakai H, Ohashi K. Association of menstrual phase with smoking behavior, mood and menstrual phase-associated symptoms among young Japanese women smokers.BMCWomens Health. 2013; 13: 10. Published online Mar 2, 2013. doi:10.1186/1472-6874-13-10
[15] Freeman EW. Premenstrual syndrome and premenstrual dysmorphic disorder: definitions and diagnosis. Psychoneuroendocrinology. 2003; 28 (3): 25-37.

[16] Pinna G, Costa EandGuidotti A. Fluoxetine and norfluoextinesterospecifically and selectively increase brain neurosteroid content at doses that are inactive on 5-HT reuptake. Psychopharmaclogy (Berl). Jan 24, 2006; 1-11.

[17] Campbell S, Monga A. PMS; Disorders of the menstrual cycle In: Gynaecology by ten teachers. Campbell S, Monga A, (Eds).AstraZeneca PLC. Arnold. 2000; Chapter 5. 61-63.

[18] Tabassum S, Afridi B, Aman Z, Tabassu W, Durrani R. Premenstrual Syndrome Frequency and severity in young college girls. J. Pak. Med Assoc Dec 2005; 55 (12) 546-9.

[19] Silberstein T. PMS; Complications of menstruation, abnormal uterine bleeding In: Current obstetric and gynaecologic diagnosis and treatment. De Cherney A.H., Nathan L. (Eds). Lange Medical books/ McGraw Hill. Medical Publishing Division. 2003; Chapter32: 623-627.

[20] Fakeye O, Olatinwo A. Dysmenorrhoea and PMS In: Comprehensive Gynaecology in the tropics. Kwawukume E.Y and Emuveyan E.E. (Eds). Graphic packaging limited Accra. 2005; Chapter 18: 168-172.

[21] Tolossa FW, Bekele ML. Prevalence, impacts and medical managements of premenstrual syndrome among female students: cross-sectional study in college of health sciences, Mekelle University, Mekelle, Northern Ethiopia. BMC Womens Health. 2014; 14: 52.Published online Mar 29, 2014. doi:10.1186/1472-6874-14-52.

[22] Masho SW, Adera T, South- Paul J. Obesity as a risk factor for Premenstrual Syndrome. J. PsychosomObstetGynaecol Mar 2005; 26 (1): 33-9.

[23] Freeman EW, Samuel SD, Rinado PJ, Sheng L. Premenstrual Syndrome as a predictor of menopausal symptoms. Obstetrics \&Gynaecology. 2004; 103: 960- 966.

[24] Weissman AM. MD. Gynaecology: Premenstrual Syndrome (PMS). University of Iowa Faily Practice Handbook, Fourth Edition. 2005: Chapter 13. Virtual Hospital.

[25] Silva CM, GiganteDP, Carret ML, Fassa AG. Population study of Premenstrual Syndrome. Rev. SaudePublica Feb. 2006; 40 (1): 47-56 (Article in Portuguese).

[26] Bernstein MT, Graff LA, Avery L, Palatnick C, Parnerowski K and Targownik LE. Gastrointestinal symptoms before and during menses in healthy women. BMC Womens Health. 2014 14: 14. Published online Jan 22, 2014. doi:10.1186/14726874-14-14.

[27] Famuyiwa OO. Psychiatric aspects of gynaecological practice In Textbook of Obstetrics and Gynaecology for medical students. Agboola A. (Ed).Second edition. 2006; Chapter 29: 244-248.

[28] Halbreich U. The etiology, biology, and evolving pathology of premenstrual syndromes.Psychoneuroendocrinology. 2003; 28 (3): 55-99.

[29] Magowan B. Menorrhagia and dysmenorrhoea.In: Magowan B. Churchill's Pocketbook of Obstetrics and Gynaecology Edinburgh: Churchill Livingstone. 1997; 179-81. 
[30] Kouri EM, Halbreich U. Hormonal treatments for premenstrual syndrome.Drugs Today. 1998; 34 (7): 603-10.
[31] Read JR, Perz J, Ussher JM. Ways of coping with premenstrual change: development and validation of a premenstrual coping measure. BMC Womens Health. 2014; 14: 1. Published online Jan 3, 2014. doi:10.1186/1472-6874$14-1$. 